Proceedings

\title{
Decentralized Drain Water Heat Recovery: Interaction between Wastewater and Heating Flows on a Single Residence Scale ${ }^{\dagger}$
}

\author{
Jan Spriet * and Aonghus McNabola \\ Department of Civil, Structural and Environmental Engineering, Trinity College, The University of Dublin, \\ 2 Dublin, Ireland; amcnabol@tcd.ie \\ * Correspondence: sprietj@tcd.ie; Tel.: +353-1896-1311 \\ + Presented at the 3rd EWaS International Conference on "Insights on the Water-Energy-Food Nexus", \\ Lefkada Island, Greece, 27-30 June 2018.
}

Published: 6 August 2018

\begin{abstract}
This paper studies the potential for drain water heat recovery on a single residence scale, showing its interaction with the space and domestic hot water heating system. The article performs a Monte Carlo simulation based on measured wastewater characteristics, and heat consumption data provided by the Building Energy Ratings database. It shows the necessity of a back-up heating system, on average between 8 and $42 \%$ of the demand can be met by recovered heat. This would signify a reduction in GHG emission varying between 7.6 and $22 \%$, but would increase costs ranging from 120 to $130 \%$. Using a hot water reservoir increases the share of recovered heat in the mix, reducing GHG emissions and costs. However at current traditional heating prices, the drain water heat recovery system for a single residence is not financially competitive with traditional systems, showing the need for different strategies.
\end{abstract}

Keywords: drain water heat recovery; single residence; wastewater and heat interaction; GWP of domestic heating systems

\section{Introduction}

In 2014, 32\% of the total primary energy consumption in Ireland was destined for thermal usage, which corresponded to $31 \%$ of the country's greenhouse gas (GHG) emissions. In the same year over $87 \%$ of this thermal energy was provided by fossil fuels, mainly oil, gas and coal, only $6.6 \%$ was provided by renewable heating sources [1]. In the European Union, heating and cooling was responsible for $50 \%$ of the final energy consumption, with a renewable share of $18 \%$ [2]. The European targets for improved energy efficiency (20\%), include an increased share of renewable energy sources (20\%), and reduced GHG emissions (20\%) by 2020 [3]. Ireland's nationally determined contribution includes a $16 \%$ increase in energy production from renewable sources ( $12 \%$ of which should be renewable heat), and a $20 \%$ reduction in GHG emission reduction [4]. At the current rate these renewable heat targets will not be reached [4]. Failure to meet these targets would require the purchase of renewable energy compliance from other EU member states [5].

The Irish domestic sector is responsible for about $45 \%$ of the thermal energy demand, and it's estimated that about $15 \%$ of the consumed heat is still embedded in water leaving residences as wastewater. Different methods for recovering this heat are discussed in literature.

These heat recovery methods range from very localized, for example in showers [6-8] and dishwashers $[9,10]$, to the combination of several residences through the sewer system [11,12]. On the other hand extremely centralized options, such as the wastewater treatment plants are also considered [13-20]. 
This paper studies the heat recovery potential from a single residence, and adds a time component to it, studying at which point in time the heat is available. It studies the interaction between this availability, and the consumption profile over a day. It's expected that the heat density of the wastewater is higher on a uni-residence scale, compared to multiple residences, however the volume will be lower. Despite an expected improved performance, the importance of the capital cost might still result in an increased cost.

\section{Methods and Analysis}

\subsection{Monte Carlo Method}

The Monte Carlo method is a probabilistic method, based on repeated random sampling of the parameters. In this case, the domestic hot water consumption, space heating consumption and wastewater temperature were randomly sampled, following their observed distribution, at each hour of the day. This method is often used for simulating systems with coupled degrees of freedom, and uncertainties on the inputs, both of which are present in the problem of estimating the recoverable heat from domestic wastewater, and its interaction with the heating system(s). For example, the domestic hot water consumption and wastewater flow are directly coupled, and uncertainties exist on the drain water temperature, and the predicted hot water consumption.

\subsection{Data}

The data used to fit the distributions and generate the random samples at each of the Monte Carlo iterations, was taken from different sources, in order to approximate actual consumption profiles as closely as possible. Some of the data was measured by the authors of this paper, other data was collected through official instances, or other research projects. The data sources are described in this section.

\subsubsection{Domestic Hot Water Consumption}

The yearly domestic energy consumption of a single residence in Ireland was collected for the attribution of a 'Building Energy Rating' (BER) to each of the residences. This BER is an indication of a residence's energy performance, it is compulsory for all rented or sold homes, with the exception of protected structures. The BER database in Ireland contained the information for 697,984 residences at the moment of the analysis, an estimated $40 \%$ of all Irish residences [21].

The yearly consumption data doesn't provide any information on daily or seasonal variations, to account for these variations a synthetic load profile was generated based on the raw data from [22]. A synthetic load profile [23] shows how the consumption (of domestic hot water in this case) at a certain point in time, relates to the mean value. The data in [22] comprised 113 dwellings, which show differences in the load profile. In order to account for these differences, a distribution was used for each hour of the day (Figure 1), and a similar profile was used for the differences for each month.

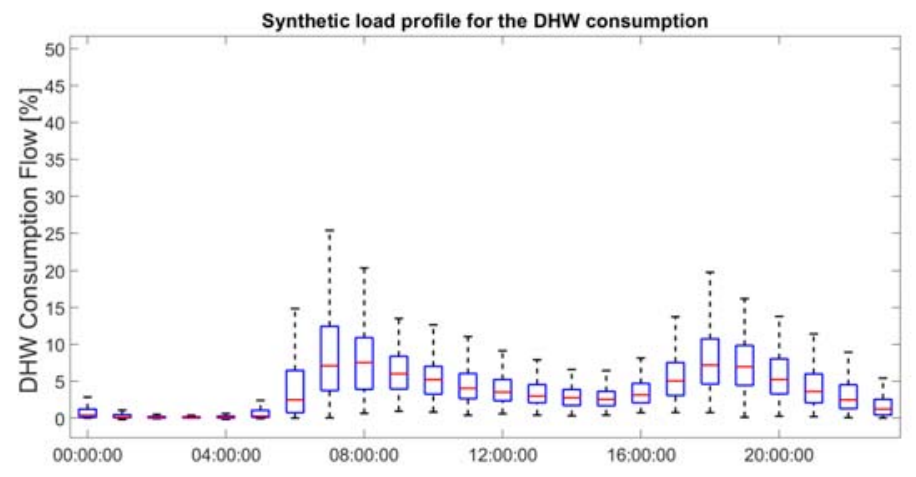

Figure 1. Synthetic hourly load profile for the domestic hot water consumption in dwellings, based on [22]. 
For each iteration of the Monte Carlo simulation, an average daily Domestic Hot Water (DHW) consumption value was generated, based on the distribution of the data in [21]. This value was then multiplied with the load profiles generated based on the distribution of the data in [22], resulting in a typical daily DHW demand profile for each of the months.

\subsubsection{Space Heating Consumption}

Similar to the DHW consumption profile, the average daily space heating consumption value was generated, based on the distribution of the data in [21]. The synthetic load profiles, and their distributions were estimated based on the heating degree day information, as given by [24]. Similarly, the typical daily space heating demand profile for each of the months was obtained through the multiplication of these parameters.

\subsubsection{Drain Water Temperature}

The drain water temperature at a certain time of the day, during a given month, was generated based on the distribution of the values measured by the authors at different residences in Ireland, an example of such a distribution is shown in Figure 2.

The waste water flow was estimated based on the DHW consumption at the given time, as the wastewater is a direct result of DHW activities.

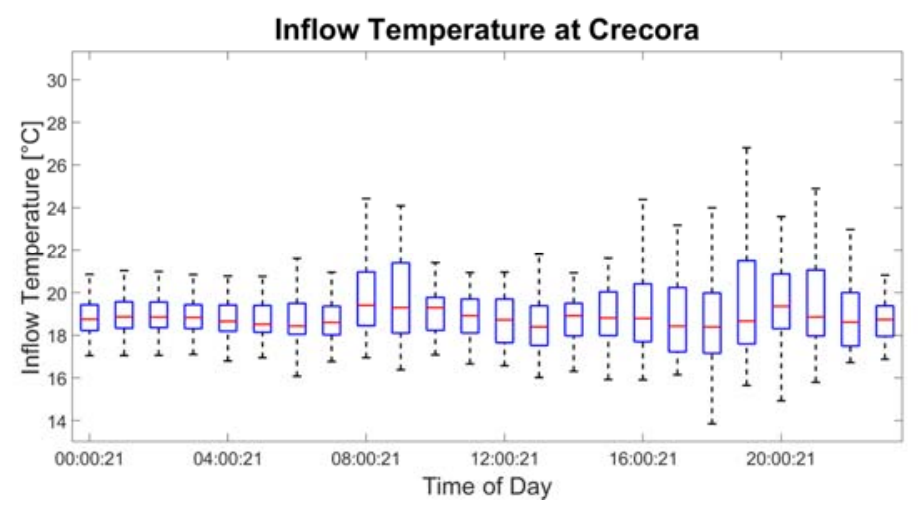

Figure 2. Temperature profile of the wastewater, observed in Ireland, during October.

\subsection{Levelized Cost of Energy}

In order to estimate the economic potential of decentralized heat recovery systems, the Levelized Cost of Energy was used. Equation (1) shows the calculation method. In this Equation $I_{n}$, is the investment, $M_{n}$ the maintenance cost, $F_{n}$ the fuel cost, $E_{n}$ the produced energy, and $r$ the discount rate, $7 \%$ in this case [25].

$$
\mathrm{LCOE}=\frac{\sum_{n=1}^{\text {lifetime }} \frac{I_{n}+M_{n}+F_{n}}{(1+r)^{n}}}{\sum_{n=1}^{\text {lifetime }} \frac{E_{n}}{(1+r)^{n}}}
$$

The investment cost consists of the heat exchanger, heat pump and installation cost. The yearly maintenance cost was estimated as a percentage of the investment, whereas the fuel costs were the average prices in Ireland, as described in [26]. The LCOE was then compared to the LCOE for classic heating systems, as given in [27].

\subsection{Total Equivalent Warming Impact}

To estimate the environmental impact of the different heating systems, the Total Equivalent Warming Impact (TEWI), divided by the produced heat was considered.

The TEWI, is based on the emissions related to the functioning of the heating devices, the emissions related to construction and decomposition of these devices were considered to be 
negligible, compared to the emissions related to the fuel [28]. The formula for heat pumps is given in Equation (2), where $G W P_{\text {refr }}$ is the global warming potential of the refrigerant, $L$ the leakage rate, $n$ the lifetime, $\alpha_{\text {recov }}$ the refrigerant recovery rate, $E_{\text {cons }}$ the electricity consumption and $K$ the carbon intensity [29].

$$
\mathrm{TEWI}=G W P_{\text {refr }} L n+G W P_{\text {refr }} m_{\text {refr }}\left(1-\alpha_{\text {recov }}\right)+E_{\text {cons }} K_{e l} n
$$

Similarly the formula for fossil fuel boiler systems is given by Equation (3), where Cons $_{\text {fuel }}$ is the fuel consumption.

$$
\text { TEWI }=\text { Cons }_{\text {fuel }} K_{\text {fuel }} n
$$

\section{System Set-Up}

The proposed system recovers the drain water and raw sewage in a collection tank, allowing for this tank to serve as a buffer to attenuate potential mismatches between the heat consumption by the heat pump and the flow of drain water. The heat contained in this holding tank is recovered through a heat exchanger, heating the primary fluid of a heat pump, which serves as the low temperature heat source for this heat pump. The heat pump is primarily used for space heating, but in case excess heat is available, it is used to heat up the feed water from the water supply to the desired temperature. The hot water is stored in the domestic hot water storage tank (DHWST), this way the heat pump can be operated continuously over a given time period, improving the performance of the heat pump, and increasing its profitability [11]. The consumed DHW is then pumped from the DHWST to match DHW demand. In case there's not enough heat available in the holding tank to provide all the space heating and DHW demand, a backup system is provided. The principal design of the system is shown in Figure 3.

The backup heating system is considered to have the same cost and carbon intensity as the overall thermal energy mix in Ireland, as given in [1].

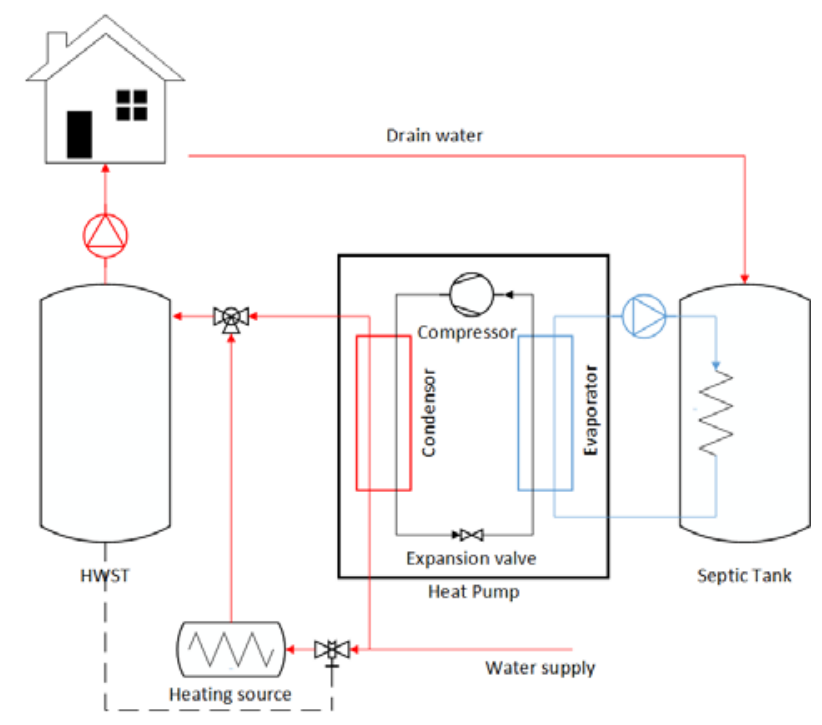

Figure 3. Principal design of the decentralized drain water heat recovery unit.

\subsection{Exploitation Strategy}

The recovered heat is primarily used to meet space heating demand, if the available energy exceeds this demand, the remaining heat is then used to meet domestic hot water demand. In case excess heat is still available this heat is used to fill the domestic hot water storage tank. Once this tank is filled to capacity the remaining heat is dumped, and thus wasted. 


\subsection{Heat Exchanger}

To recover the heat embedded in the wastewater a heat exchanger is placed in the wastewater holding tank. In this analysis a copper heat exchanger was considered. This device was required to ensure the physical separation between the wastewater and heating and hot water network.

\subsubsection{Heat Exchange Surface}

The heat exchange surface was determined using the log mean temperature difference method, as shown in Equation (4). Where $F$ is a correction factor based on the heat exchanger type, $A_{s}$ the exchange surface and $U$ the heat transfer coefficient of the heat exchanger.

$$
\dot{Q}_{H E}=F A_{S} U \Delta T_{L M T D}
$$

\subsubsection{Heat Exchanger price}

The price of the heat exchanger was determined using the Vatavuk method, shown in Equation (5), and described in [31].

$$
E_{c}=885 \times A_{s}^{0.432}
$$

\subsection{Heat Pump}

A heat pump is commonly used to convert low grade heat (at low temperature), to high grade heat, this process does not happen spontaneously, the input of mechanical work is required.

\subsubsection{Heat Pump Performance}

The performance of a heat pump is described as the ratio of the produced heat and the electric input, this ratio is called the Coefficient of Performance (COP, Equation (6)).

$$
C O P=\frac{Q_{\text {out }}}{W_{\text {in }}}
$$

The higher this ratio, the lower the required work input, and thus fuel consumption, for the production of a certain amount of heat. This performance is calculated using a regression on the relationship between the required temperature lift (temperature difference between the low temperature heat source and the high temperature heat sink), and the COP, obtained from the datasheets of different heat pumps, with a rated power below $7 \mathrm{~kW}$. The regression formula is given in Equation (7).

$$
C O P=8.27-0.10 \times T L
$$

\subsubsection{Heat Pump Price}

The price of the heat pump was determined by regression on the catalogue price of 28 heat pumps, with a rated power below $7 \mathrm{~kW}$. The regression formula is given in Equation (8).

$$
\text { Price }_{H P}=8831\left(Q_{\text {out }, \text { rated }}\right)^{-1.09} \times Q_{\text {out }, \text { rated }}
$$

\section{Results and Discussion}

The analysis shows that the need for the back-up heating system is greatest right after the demand peaks ( 8 a.m. and 6 p.m.), lagging the points of high production from the DWHR system. During the periods of low demand (3-4 p.m.), peak burner activity is often not required.

Due to mismatching between heat recovery and heat consumption, the average share of heat demand met by the DWHR system without a hot water reservoir is on average $8.2 \%$, by adding a hot water reservoir of $300 \mathrm{~L}$ this can be increased up to $42.4 \%$. This can be explained by the higher usage rate of the recovered energy, from $75 \%$ to $99 \%$. This shown in Figure 4. 


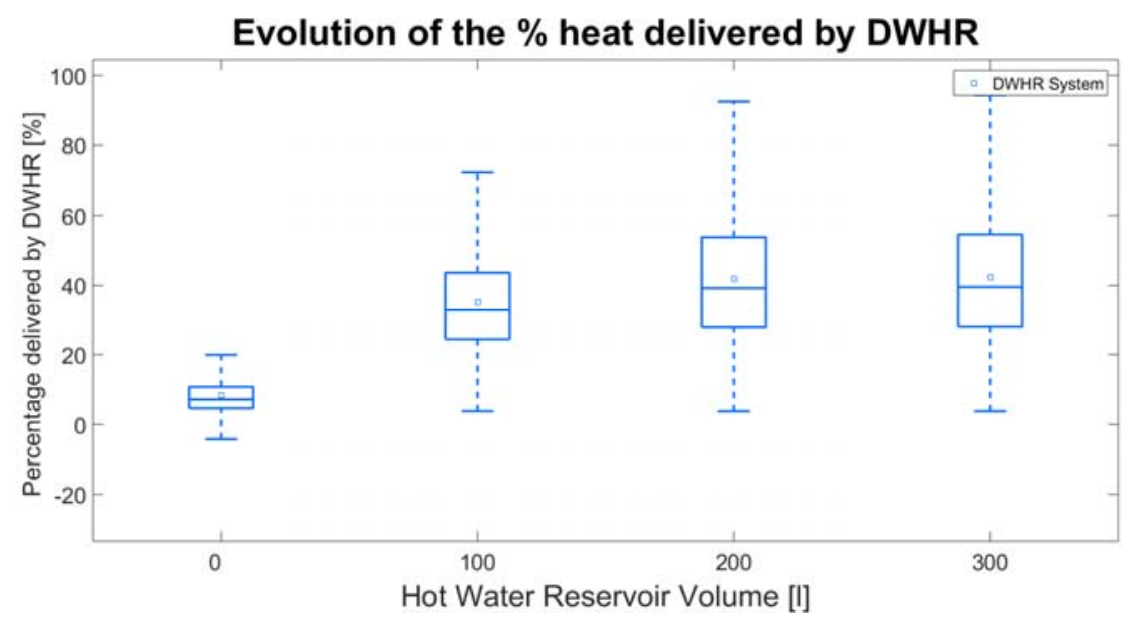

Figure 4. Evolution of the yearly average share of heat delivered by the DWHR system.

Due to the high capital costs the LCOE remains significantly higher than the average value in the current thermal energy mix, as can be seen in Figure 5. Implementing this heat recovery method would result in a yearly increased cost of heating ranging between $630 €$ and $680 €$.

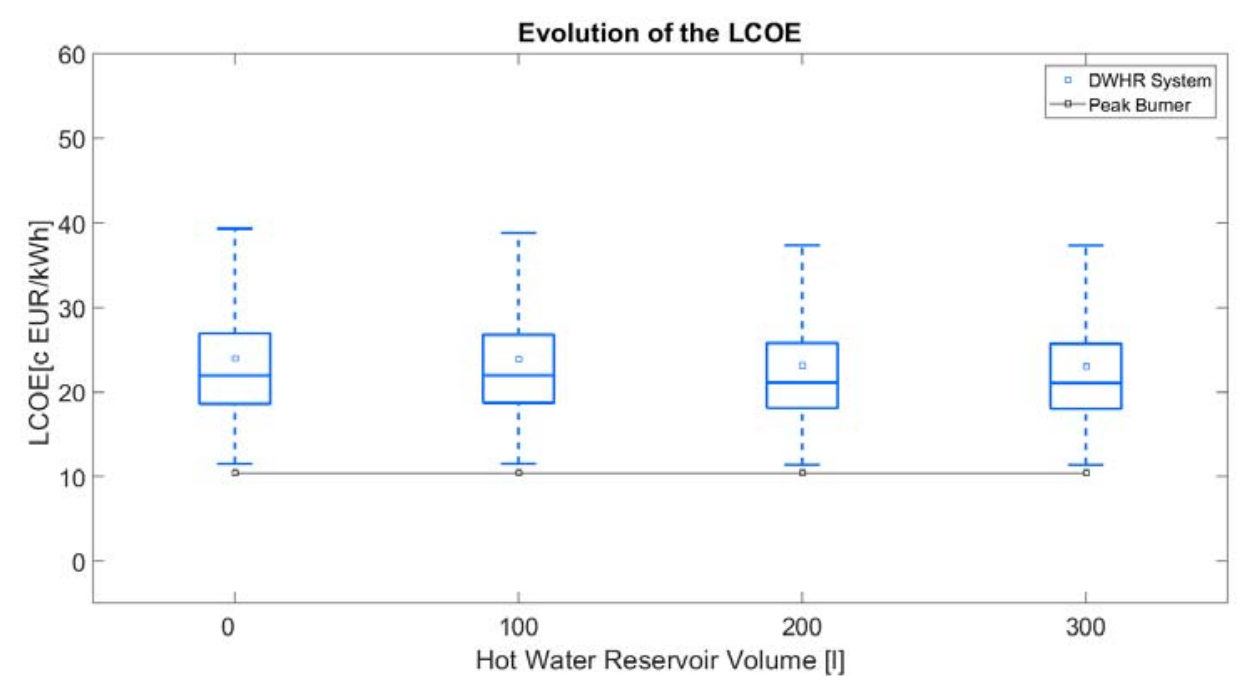

Figure 5. Evolution of the Levelized Cost of Energy with hot wat reservoir size.

Figure 6 shows a decrease in TEWI per kWh of heat with increased hot water reservoir volume, as compared to the TEWI of the average thermal energy mix, resulting in an average reduction in $\mathrm{CO}_{2 \text {,eq }}$ emissions varying between $109.25 \mathrm{~kg} \mathrm{CO}_{2 \text {,eq }}$ and $315.82 \mathrm{~kg} \mathrm{CO}_{2, \text { eq }}$ per year for an average residence.

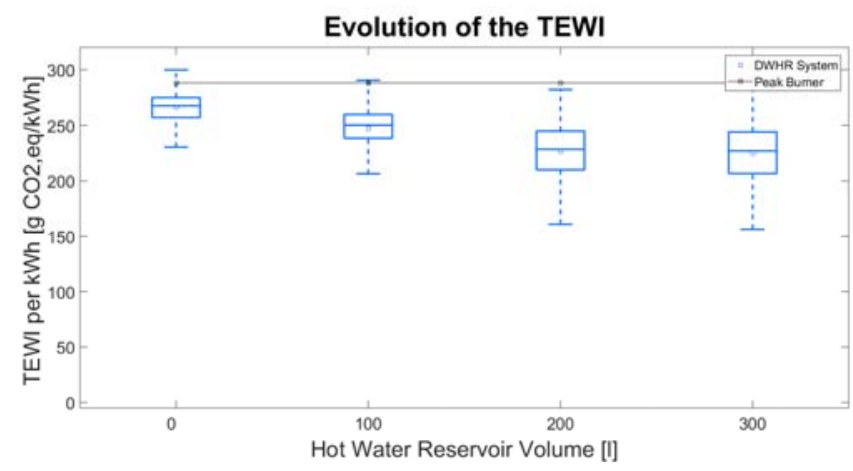

Figure 6. Evolution of the Total Equivalent Warming Impact per $\mathrm{kWh}$ with hot wat reservoir size. 


\section{Conclusions \& Perspectives}

When using a drain water heat recovery system, a back-up heating system remains necessary. It is generally used right after the consumption peaks, when the accumulated recovered heat is depleted to meet the peak in demand. The share of heat demand that can be met by the DWHR system varies between $8 \%$ and $42 \%$. Due to a mismatch between the availability of waste water heat and the heat demand, recovered heat could be wasted. In order to avoid this a hot water reservoir can be used to store the recovered heat. Using a hot water reservoir of $300 \mathrm{l}$ can reduce the amount of recovered heat that is unused from $25 \%$ without a reservoir to $99 \%$, with a reservoir. This shows a mismatch between heat demand and the availability of heat in the wastewater.

Using the DWHR system greenhouse gas emissions related to domestic hot water- and space heating can be reduced by $7.6 \%$ to $22 \%$. However, this increases heating costs by a factor ranging from $120 \%$ to $130 \%$. At current traditional heating prices, the DWHR system for a single residence is not financially competitive with traditional systems, due to its important capital investment. Combining waste water streams from different residences would provide a larger flow, and potentially a high recoverable energy volume. However, heat would be lost between the residence and the collection point, reducing the energy density of the waste water. In turn this could lead to an increased GHG intensity of the recovered heat. An optimal collection point should be found, considering the trade-off between increased energy volume and reduced energy density.

Author Contributions: The research for this paper has been conducted by J.S. under the supervision of A.M.N.

Funding: The present research has been supported and funded by the ERDF Interreg Ireland-Wales Programme 2014-2020.

Acknowledgments: This research is part of the Dŵr Uisce project.

Conflicts of Interest: The authors declare no conflict of interest. The founding sponsors had no role in the design of the study; in the collection, analyses, or interpretation of data, and in the writing of the manuscript.

\section{References}

1. Howley, M.; Dineen, Holland, M.; Dineen, D.D. Energy in Ireland Key Statistics 2015; Sustainable Energy Authority of Ireland: Dublin, Ireland, 2015.

2. European Commision. An EU Strategy on Heating and Cooling; European Commision: Brussels, Belgium, 2016.

3. Latvia and European Commission. Intended Nationally Determined Contribution of the EU and its Member States; Latvia and European Commission: Riga, Latvia, 2015.

4. Scheer, J.; Clancy, M.; Gaffney, F. Ireland's Energy Targets-Progress, Ambition and Impacts; Sustainable Energy Authority of Ireland: Dublin, Ireland, 2016.

5. Sustainable Energy Authority of Ireland. Achieving Ireland's 2020 Renewable Heat Target; Sustainable Energy Authority of Ireland: Dublin, Ireland, 2015.

6. McNabola, A.; Shields, K. Efficient drain water heat recovery in horizontal domestic shower drains. Energy Build. 2013, 59, 44-49.

7. Wong, L.T.; Mui, K.W.; Guan, Y. Shower water heat recovery in high-rise residential buildings of Hong Kong. Appl. Energy 2010, 87, 703-709.

8. Slys, D.; Kordana, S. Financial analysis of the implementation of a Drain Water Heat Recovery unit in residential housing. Energy Build. 2014, 71, 1-11.

9. Paepe, M.D.; Theuns, E.; Lenaers, S.; Loon, J.V. Heat recovery system for dishwashers. Appl. Therm. Eng. 2003, 23, 743-756.

10. Hua, L. Heat Exchanger Development for Waste Water Heat Recovery. Master's Thesis, University of Canterbury, Canterbury, New Zealand, 2005.

11. Spriet, J.; Hendrick, P. Wastewater as a Heat Source for Individual Residence Heating: A Techno-economic Feasibility Study in the Brussels Capital Region. J. Sustain. Dev. Energy Water Environ. Syst. 2017, 5, 289-308.

12. Li, F.; Zheng, G.; Tian, Z. Optimal operation strategy of the hybrid heating system composed of centrifugal heat pumps and gas boilers. Energy Build. 2013, 58, 27-36. 
13. Chae, K.-J.; Kang, J. Estimating the energy independence of a municipal wastewater treatment plant incorporating green energy resources. Energy Convers. Manag. 2013, 75, 664-672.

14. Song, Y.; Yao, Y.; Ma, Z.; Na, W. Study of Performance of Heat Pump Usage in Sewage Treatment and Fouling Impact on System. In China Renewable Energy Resources and a Greener Future; ICEBO: Shenzhen, China, 2006.

15. Zhou, W.Z.; Li, J.X. Sewage Heat Source Pump System's Application Examples and Prospect Analysis in China. In Proceedings of the International Refrigeration and Air Conditioning Conference, Purdue, IN, USA, 12-15 July 2004.

16. Chen, H.L.; Dai, X.D. Economic Analysis of a Waste Water Resource Heat Pump Air-Conditioning System in North China. In Renewable Energy Resources and a Greener Future; ICEBO: Shenzhen, China, 2006.

17. Yan, X.L.; Tao, L.H. Study on Reutilization of Heat Energy from Municipal Wastewater. In Proceedings of the 9th International Conference on Environmental Science and Technology, Houston, TX, USA, 25-29 June 2018.

18. Gu, Y.; Deng, H.; Gao, Y.; Zhang, H. The potential of urban wastewater heat: The feasibility analysis of using wastewater source heat pump. In Proceedings of the 2011 International Symposium on Water Resource and Environmental Protection, Xi' an, China, 20-22 May 2011.

19. Kretschmer, F.; Neugebauer, G.; Kollmann, R.; Eder, M.; Zach, F.; Zottl, A.; Narodoslawsky, M.; Stoeglehner, G.; Ertl, T. Resource recovery from wastewater in Austria: Wastewater treatment plants as regional energy cells. J. Water Reuse Desalin. 2016, 6, 421-429.

20. Neugebauer, G.; Kretschmer, F.; Kollmann, R.; Narodoslawsky, M.; Ertl, T.; Stoeglehner, G. Mapping Thermal Energy Resource Potentials from Wastewater Treatment Plants. Sustainability 2015, 7, 1298813010.

21. SEAI. Building Energy Rating Certificate (BER); SEAI: Dublin, Ireland, 2017.

22. EST. Measurement of Domestic Hot Water Consumption in Dwellings; EST: London, UK, 2011.

23. Pillai, G.G.; Putrus, G.A.; Pearsall, N.M. Generation of synthetic benchmark electrical load profiles using publicly available load and weather data. Int. J. Electr. Power Energy Syst. 2014, 61, 1-10.

24. Eireann, Met. Degree Days. Available online: http://www.met.ie/climate/degree-day.asp (accessed on 30 April 2018).

25. Rushing, A.S.; Kneifel, J.D.; Lippiatt, B.C. Energy Price Indices and Discount Factors for Life-Cycle Cost Analysis; NIST: Gaithersburg, MD, USA, 2013.

26. Howley, M.; Holland, M. Electricity $\mathcal{E}$ Gas Prices in Ireland; US Department of Commerce: Washington, DC, USA, 2016.

27. Wang, Z. Trade-offs in Levelized Cost of Herat among different domestic heating technologies. In Proceedings of the All Energy Conference, Glasgow, UK, 10-11 May 2017.

28. Zott, A.; Lindahl, M.; Nordman, R.; Rivière, P.; Miara, M. Evaluation Method for Comparison of Heat Pump Systems with Conventional Heating Systems; The European Commission: Brussels, Belgium, 2011.

29. SEAI. What Are the Carbon Emission Factors Used? Sustainable Energy Authority of Ireland: Dublin, Ireland, 2016.

30. Taal, M.; Bulatov, I.; Klemeš, J.; Stehlik, P. Cost estimation and energy price forecasts for economic evaluation of retrofit projects. Appl. Therm. Eng. 2003, 23, 1819-1835.

31. Wallin, J.; Claesson, J. Analyzing the efficiency of a heat pump assisted drain water heat recovery system that uses a vertical inline heat exchanger. Sustain. Energy Technol. Assess. 2014, 8, 109-119.

32. Yunus, C.; Michael, A.B. Thermodynamics: An Engineering Approach, 6th ed.; McGraw Hill: New York, NY, USA, 2007.

(C) 2018 by the authors. Licensee MDPI, Basel, Switzerland. This article is an open access article distributed under the terms and conditions of the Creative Commons Attribution (CC BY) license (http://creativecommons.org/licenses/by/4.0/). 